\title{
MEMBRANE-BASED DOWNSTREAM PROCESSING OF MICROBIAL XYLITOL PRODUCTION
}

\author{
Ria Desiriani $^{1}$, M.T.A.P Kresnowati ${ }^{1 *}{ }^{\text {I.G.Wenten }}{ }^{1}$ \\ ${ }^{1}$ Department of Chemical Engineering, Bandung Institute of Technology, Bandung, West Java, 40132, \\ Indonesia
}

(Received: January 2017 / Revised: May 2017 / Accepted: October 2017)

\begin{abstract}
Xylitol is a sugar alcohol used as a sweetener in the food industry. Xylitol can be produced from D-xylose using a fermentation process, but it then needs to be separated from the other components of the fermentation broth (e.g., metabolic products, residual substances, biomass cells, and mineral salts), before being purified as xylitol crystals. Therefore, to obtain high purity xylitol, various separation processes are required. One very promising downstream processing method is membrane separation. This study evaluated membrane-based processes for the separation of biomass cells and other impurities, determined the concentration of xylitol produced from Debaryomyces hansenii yeast fermentation broth, and proposed a polysulfone ultrafiltration (UF) membrane for biomass-cell separation followed by polyamide nanofiltration (NF) to remove low-molecular-weight compounds (e.g., acetic acids) from sugars. The effects of operating pressure were examined using a fermentation broth model solution. The results showed that a higher pressure caused a higher permeate flux; however, the permeate flux's rate flow decreased over time due to concentration polarization, and fouling in the UF and NF membranes. Nevertheless, at all pressures, UF achieved a 99\% rejection of biomass cells. In addition, microscope analysis showed that no biomass cells were detected in the permeates of UF. The resulting NF concentrates revealed high xylitol retention and a beneficially lower concentration of acetic acids. The operating pressures of the UF test conditions were $1 \mathrm{barg}$ and $1.5 \mathrm{barg}$, illustrating that, at a pressure of $5.5 \mathrm{barg}$, the experiments achieved reasonably high xylitol retention (above 90\%) indicating negligible losses of sugar in the permeate port. Moreover, this was proven to be a feasible way to concentrate xylitol up to three times from the initial concentration of the model fermentation broth (MFB). Therefore, the results demonstrated that a two-stage combination of UF and NF is a promising system for the downstream processing of microbial xylitol production.
\end{abstract}

Keywords: Biomass cells; Fermentation broth; Nanofiltration; Ultrafiltration; Xylitol

\section{INTRODUCTION}

Xylose is a five-carbon sugar within the aldehyde group, and is the second most abundant sugar in nature (Guirimand et al., 2015). Xylitol is a five-carbon sugar alcohol that can be found naturally in fruits such as strawberries, in low quantities. Xylitol has many applications as a sweetener; for example, it can safely be consumed by diabetic people and it has sweetness equal to sucrose, it is used as an additive in color photography, and helps to prevent dental cavities (Murthy et al., 2005; Sjoman et al., 2008). Xylose can be converted to xylitol by a chemical and

\footnotetext{
*Corresponding author's email: kresnowati@che.itb.ac.id, Tel: +62812-2028878, Fax: +6222 2501438 Permalink/DOI: https://doi.org/10.14716/ijtech.v8i8.726
} 
biological process (Murthy et al., 2005). In the chemical process, xylose is hydrogenated at a high pressure and temperature using a ruthenium catalyst (Yadav et al., 2012). Meanwhile, in the biological process, xylose can be converted to xylitol by utilizing yeasts as microbial conversions. This alternative method is attractive due to its low energy consumption, high substrate specificity, and it produces fewer toxic compounds (Nguyen et al., 2015).

The fermentation broth not only contains xylitol but also contains a residual substrate, acetic acid, and ethanol was detected as another metabolic product (Kresnowati et al., 2016). In order to enhance xylitol's purity, other components of the fermentation broth should be removed. Furthermore, these components can also be potentially valuable products if they can be separated from the fermentation broth.

Many methods have been considered as an alternative for removing impurity components, such as vacuum evaporation, extraction, over liming, activated carbon adsorption, and ion exchange (Zhou et al., 2013a; Weng et al., 2010). However, they require high energy for the operation or they can lose minor products of fermentation (Zhou et al., 2013a; Sjoman et al., 2008). Therefore, advanced separation methods such as a membrane-based process have been considered. Affleck (2000) evaluated an ultrafiltration-(UF) based process for the downstream processing of xylitol produced via fermentation. Another research project proposes the combination of UF and NF membrane processes, and considers the advantages and limitations of each process (Kresnowati et al., 2017).

Membrane technologies are used for the downstream processing of biological processes, due to their simple operation and their ease of scaling up (Sasaki et al., 2014). In particular, the pressure-driven membrane is effective and has a good performance for industrial production processes (Zhou et al., 2013b; Nguyen et al., 2015). UF and NF are two types of pressuredriven membrane processes. Integrated UF and NF technology is proposed for improving the economic viability of the downstream process, so a combined technology has been used for various purification processes.

UF membranes have a molecular weight cut-off (MWCO) of 1,000-100,000 Da. This means that all substances larger than the MWCO of a particular membrane, such as microorganisms and macromolecules (proteins, carbohydrates, and fat), are retained on the membrane surface, while the substances smaller than the MWCO, such as sugars, salt minerals, and water, can pass though the membrane (Li et al., 2006). To prove the capability of UF, lab-scale experiments have been carried out; for example, particular substances with larger polymeric cellulose $>10$ $\mathrm{kDa}$ from the enzymatic hydrolysis of cellulose from pretreated wood was retained on a UF membrane surface (Abels et al., 2013).

NF can be used for the separation and concentration of products from streams, such as fermentation product separation and sugar concentration. NF has a special characteristic in that the MWCO varies from 150-1,000 Da, so using this membrane can retain multivalent compounds that have an MWCO of 150-250 Da, such as saccharides. In Zhou et al.'s (2013a) study, NF was used to separate xylose and acetic acid in synthetic model solutions at a ratio of 10:1, respectively. Their results show that the highest separation factor achieved for acetic acid was 5.4. They report the optimum filtration pressure is 24.5 barg at a cross-flow velocity of $0.09 \mathrm{~m} / \mathrm{s}$. However, the concentration of xylose on the membrane surface was higher, at 238 $\mathrm{g} / \mathrm{L}$.

In our study, we evaluated a membrane-based separation process using a combination of UF and NF to isolate and concentrate xylitol from a fermentation broth of Debaryomyces hansenii yeast using a synthetic medium containing xylose as a substrate. UF was conducted to remove cells and other macromolecules from the fermentation broth. Sequentially, the permeate was further filtered using an NF membrane. 
The aim of this study was to evaluate the performance of UF and NF for separating impurities from a fermentation broth; in particular, the effects of operating pressure on optimizing the separation membrane and efficiently concentrating xylitol from the fermentation broth were investigated.

\section{METHODOLOGY}

\subsection{Field Data Analysis}

The membrane was fed using a fermentation-broth solution (model fermentation broth (MFB)), obtained from the fermentation of $D$. hansenii yeast using a synthetic medium containing xylose as the carbon source; this was done by following the procedure explained in a prior study (Mardawati et al., 2015). Pure xylitol was added to the solution to increase its concentration in the solution. The properties of the feed solutions are shown in Table 1.

Table 1 Compositions of feed solutions used for the membrane-filtration experiments

\begin{tabular}{lc}
\hline \multicolumn{1}{c}{ Properties } & Concentration \\
\hline Xylose $(\mathrm{g} / \mathrm{l})$ & 2.70 \\
Xylitol $(\mathrm{g} / \mathrm{l})$ & 2.80 \\
Acetic acid $(\mathrm{g} / \mathrm{l})$ & 2.90 \\
Dry weight cell $(\mathrm{g} / \mathrm{l})$ & 4.02 \\
\hline
\end{tabular}

\subsection{Membranes}

A hydrophilic polysulfone UF membrane (GDP Filter, Indonesia) with MWCO 1,000-5,000 Da was used in this study as the first-stage separation. A hollow fiber membrane module with a total area of filtration of $2.51 \mathrm{~m}^{2}$ was used. For the second-stage separation, a polyamide NF membrane with an MWCO of 150-300 Da (DOW Filmtec Corp) in spiral-wound module configuration was chosen. The filtration area of the NF membrane was $0.42 \mathrm{~m}^{2}$. The experiment design shown in Table 2 was used to investigate the effect of various operating pressures for UF and NF on the component retention and permeate flux decline.

Table 2 Experimental conditions to determine the influence of the operating conditions on component separation

\begin{tabular}{cc}
\hline Pres. UF (barg) & Pres. NF (barg) \\
\hline 0.5 & 5.5 \\
1.0 & 6.5 \\
1.5 & 7.5 \\
2.0 & 8.5 \\
\hline
\end{tabular}

\subsection{Membrane Configuration and Working Procedure}

The separation system was used on a batch operation in which the retentate stream was fully recycled back into the feed tank and the permeate stream was fed into the next step. This operation assisted the concentration of sugars in the MFB. It is also commonly applied to laboratory- and pilot-scale studies (Cheryan, 1998).

Figure 1 shows a schematic representation of the proposed process. The systems consisted of re-circulating pumps and a cross-flow membrane module. All filtration systems were carried out at ambient room temperature. The system included a UF membrane as the first stage of the downstream process. Initially, a feed of MFB (4 L) was transferred to the feed storage tank with a diaphragm pump. 


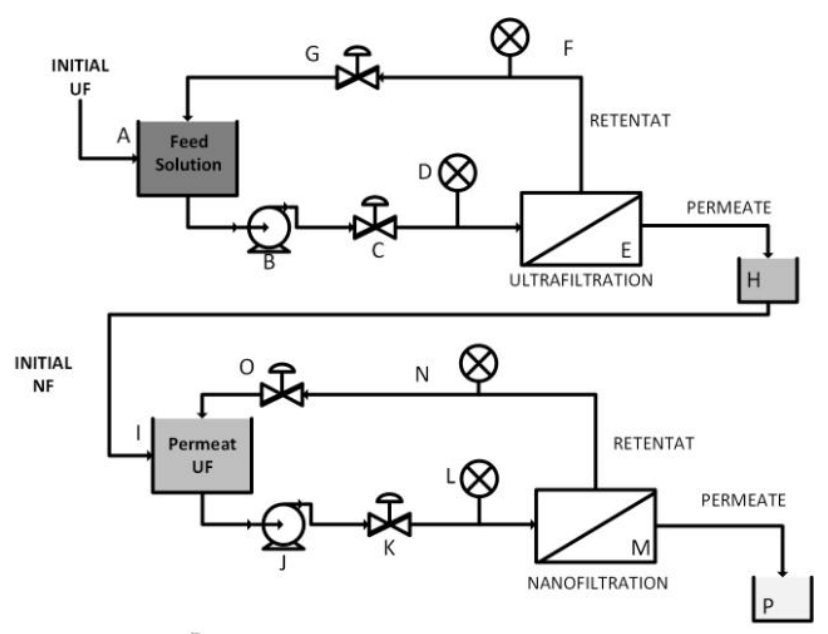

Figure 1 Schematics diagram process for these experiments. (A) Storage tank feed solution; (B, J) Pump; (C,G,K,O) Valve; (D,F,L,N) Pressure gauge; (E) UF membrane; (M) NF membrane; (I) Storage tank of permeate UF; (H,P) Permeate solutions

The pressure was adjusted using a needle valve. The pressure gauges were also utilized to measure the pressure in the feed and retentate line. The cross-flow velocity was unvarying in both membranes. The flux was measured by timing how long it took for $100 \mathrm{ml}$ of permeate to be produced using a stopwatch. The needle valve was throttled slowly to set the desired pressure, as shown in Table 1. The filtration was done when the total permeate flux reached 3.2 liters, and the retentate was circulated back to the storage feed tank. The permeate of the UF membrane was used for the filtration experiments with the NF membrane, which was the second stage of the downstream process. This solution was transferred to the feed tank of the NF with a centrifugal pump of up to 40 barg. Each filtration was performed until a steady permeate flux was reached. After each experiment, both the UF and NF membranes were cleaned using $\mathrm{NaOH} 0.1 \mathrm{~N}$ for 15 minutes, at 0.5 barg for UF and at 2 barg for $\mathrm{NF}$, to remove the solutes deposited on the membrane surface. Before and after the membranes were used and cleaned, the pure water flux was measured using demineralized water as the feeding solution. Samples with a small volume $(3 \mathrm{ml})$ were taken from the feed, permeate, and final retentate for analysis.

\subsection{Analytical Methods}

The samples from the feed, permeate, and retentate were centrifuged at $6000 \times \mathrm{g}$ (for 10 minutes), and the supernatants were taken to determine the concentration of the xylitol and the other metabolites using high-performance liquid chromatography (HPLC) with a BioRad Aminex HPX-87H column, which was applied using $5 \mathrm{mM} \mathrm{H}_{2} \mathrm{SO}_{4}$ as an eluent (Mardawati et al., 2015). Prior to the injection, the samples were filtered using a $0.2 \mu \mathrm{m}$ membrane filter.

The yeast cells were measured by microscopic observation (Olympus $\mathrm{CH} 20$ ) using methylene blue test staining to verity cell viability (Martınez et al., 2003).

\subsection{Rejection and Permeate Flux}

The extent of xylitol concentration obtained by applying the membrane process is presented in terms of $\%$ rejection, flux, volume concentration factor. The rejection of the main component was calculated using Equation 1:

$$
\% R=\left(1-\frac{C_{\text {permeat }}}{C_{\text {retentat }}}\right) \times 100
$$


where $\mathrm{C}_{\text {permeat }}$ represents the concentration of the component in the permeate stream and $\mathrm{C}_{\text {retentat }}$ is the concentration of the components in the retentate stream. The permeate flux $(\mathrm{J})$ is the volume of permeate collected per unit area of the membrane (A) and per unit of time (t), as shown in Equation 2:

$$
\begin{gathered}
I=\frac{V}{A x t} \\
I_{w}=\frac{r_{p}^{2} \Delta P}{8 \mu\left(\frac{\Delta x}{A_{k}}\right)}
\end{gathered}
$$

\section{RESULTS AND DISCUSSION}

\subsection{Pure Water Flux Measurement}

The pure water flux was measured at ambient temperature. This is a basic parameter used to evaluate membrane performance. The operating pressure versus water flux curves were plotted for both the UF and NF membranes, as shown in Figure 2.

A.

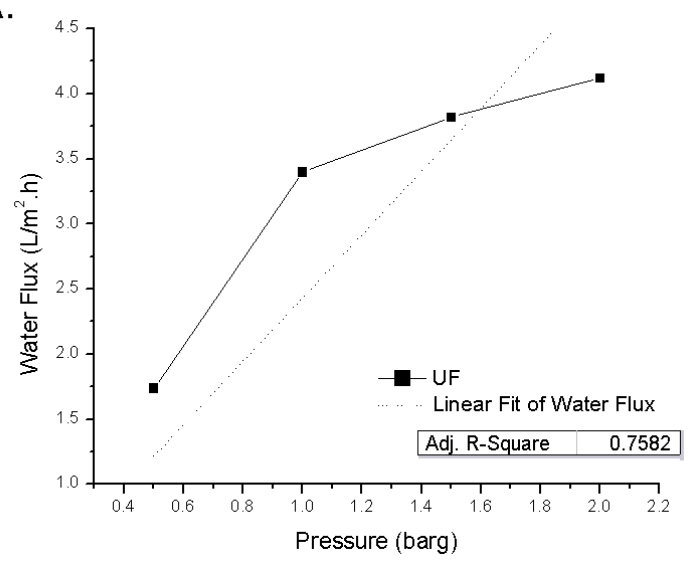

B.

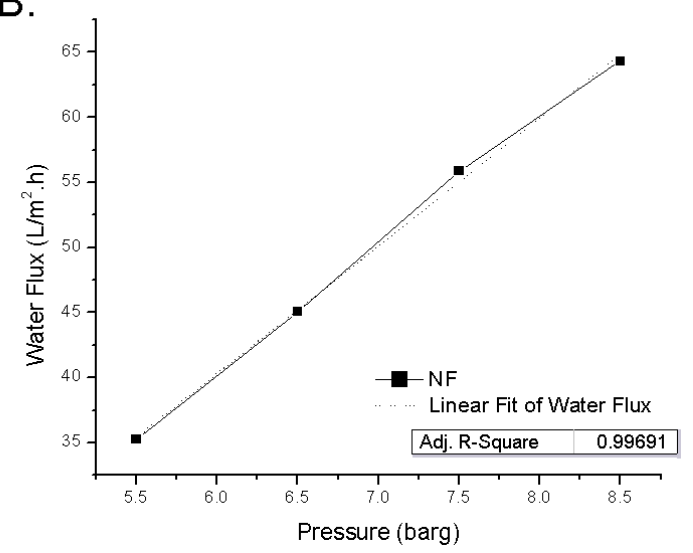

Figure 2 Water Flux of UF (a) and NF (b) against varied pressure at ambient temperature

High linear correlations were obtained between water flux and various pressures, as presented in Figure 2, with $\mathrm{R}^{2}=0.7582$ for $\mathrm{UF}$ and $\mathrm{R}^{2}=0.9969$ for NF. It is obvious that the water flux of the UF membranes was lower than the NF membranes, due to the difference in membrane characteristics. The obtained results agree with the Hagen-Poiseuille equation (Equation 3), which show that the pure water flux $\left(\mathrm{J}_{\mathrm{w}}\right)$ increased linearly with pressure $(\Delta \mathrm{P})$.

\subsection{UF of MFB}

As can be seen in Figure 3, at a lower pressure, a small permeate flux was obtained during initial filtration. A different trend was observed from the other applied pressure, but a similar initial permeate flux was observed, 2, 2.2, and $2.24 \mathrm{~L} / \mathrm{m}^{2} . \mathrm{h}$, at pressures of 1, 1.5, and $2 \mathrm{barg}$, respectively. A severe reduction of permeate flux was shown at a higher pressure; at the beginning of the filtration the permeate flux decreased sharply over time. The decline of permeate flux for UF was gradual due to cake formation on the surface of the membrane under operational conditions ( $\mathrm{Li}$ et al., 2006). Over time, the deposited cake formation gets thicker, which may lead to irreversible fouling of the UF membrane. Considering the decrease in permeate flux, the optimum pressure of UF was observed at 1 barg. Using microscopic observation, there were no cells detected in the permeate of UF, whereas the total amount of cells observed in the UF retentate was $10.32-15.52 \times 10^{7}$ cells $/ \mathrm{ml}$. 


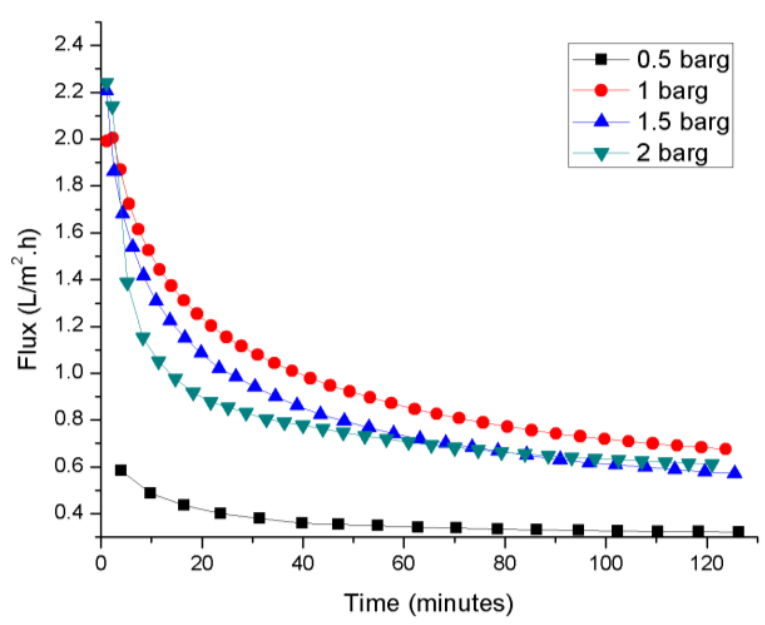

Figure 3 Change of permeate flux over the time during UF

Table 3 represents the steady fluxes found at a pressure range from $0.5-2$ barg during the filtration of MFB with the UF membrane. The results showed that, at $1 \mathrm{barg}$, a higher steady flux of $0.680 \mathrm{~L} / \mathrm{m}^{2}$.h was achieved. A further increase in pressure from 1.5 to 2 barg gave lower steady fluxes of 0.571 and $0.612 \mathrm{~L} / \mathrm{m}^{2} . \mathrm{h}$, respectively.

Table 3 Steady fluxes at differences pressure of UF membrane

\begin{tabular}{cc}
\hline Pres. (barg) & Steady fluxes $\left(\mathrm{L} / \mathrm{m}^{2} . \mathrm{h}\right)$ \\
\hline 0.5 & 0.318 \\
1 & 0.680 \\
1.5 & 0.571 \\
2 & 0.612 \\
\hline
\end{tabular}

\subsection{NF of UF Permeate}

Figure 4, shows the effect of pressure and time on permeate fluxes during the filtration of the MFB at pressures ranging from 5.5-8.5 barg for NF. We observed an increase in the initial permeate fluxes with an increase in applied pressure. On the other hand, we also observed a steeper decrease in the permeate flux with an increase in the applied pressure. Overall, a higher flux was a reached at a higher applied pressure in Table 4.

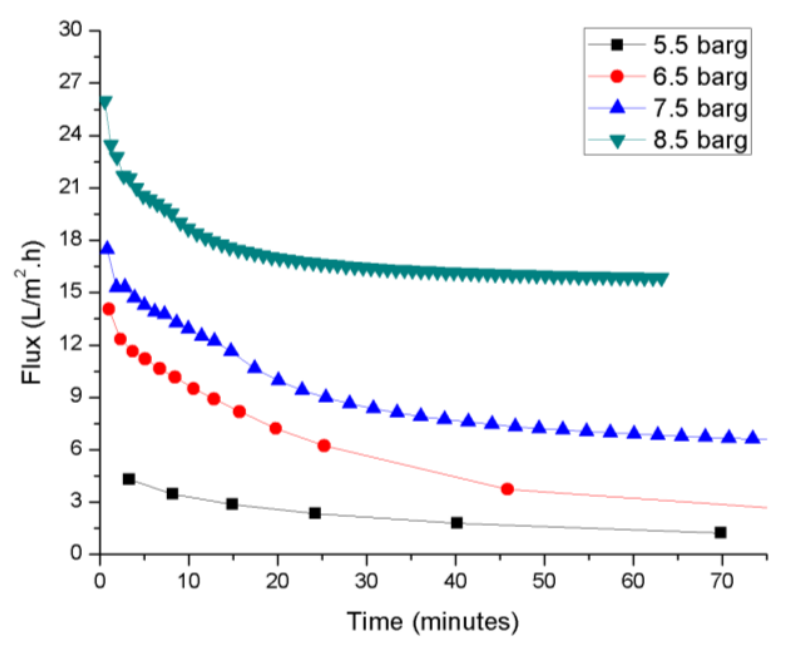

Figure 4 Change of permeate flux over time during the filtration of MFB for NF 
Table 4 Steady fluxes at different pressures of NF membrane

\begin{tabular}{cc}
\hline Pres. (barg) & Steady fluxes $\left(\mathrm{L} / \mathrm{m}^{2} . \mathrm{h}\right)$ \\
\hline 5.5 & 1.23 \\
6.5 & 1.95 \\
7.5 & 6.31 \\
8.5 & 15.84 \\
\hline
\end{tabular}

At an increased pressure, more solutes are transported to the membrane surface, which causes the concentration polarization and membrane fouling that leads to the reduction of the permeate flux (Zhou et al., 2013a). Under a high concentration slope, the solutes have a tendency to transmigrate though the membrane (Lyu et al., 2016). In general, this phenomenon occurred when batch-filtration mode was applied, and the retentate was recycled back to the feed storage tank and sent back to the filter. Therefore, an increase in filtration time caused the deposition of retained particles and macromolecule substances on the membrane surface.

Figure 5 shows that xylitol retention increased from $95 \%$ at 5.5 barg to $97 \%$ at 8.5 barg in a similar observation. A further increase in the applied pressure did not result in a further increase in xylitol retention. From another application of an NF-membrane-based process for concentrating activated carbon, with treated pre-hydrolysis liquor (TPHL) for the fermentation substrate, a pressure increase from 100 to 500 psi was shown to increase the total sugar concentration from 360 to $480 \mathrm{~g} / \mathrm{L}$ (Ahsan et al., 2014). Another result is revealed by Nguyen et al. (2015), who find that NF was the optimum membrane for initiating a detoxification effect on a lignocellulosic hydrolysate model solution, with glucose retention $>94 \%$ and inhibitor transmission $>80 \%$. NF offers a higher flux and lower pressure. However, the final conclusion is that xylitol retention reached significantly high values when the pressure was increased.

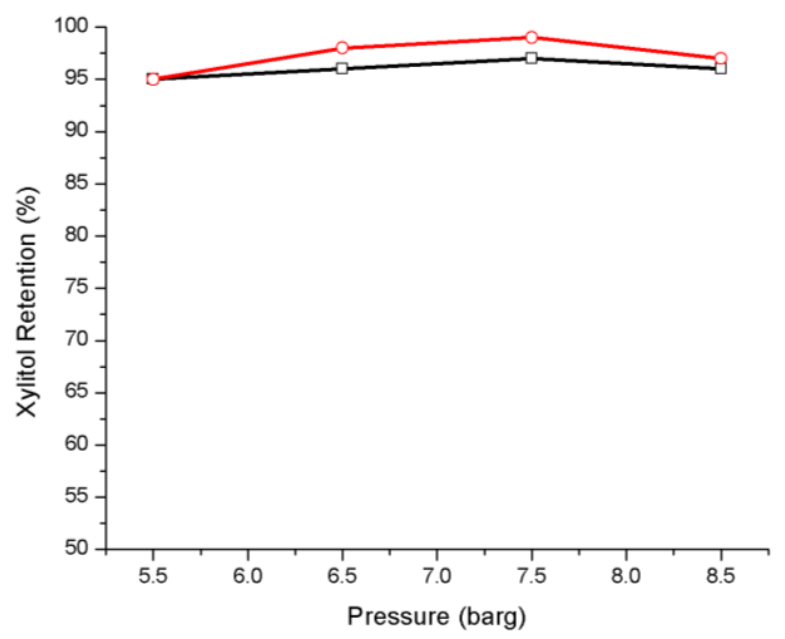

Figure 5 Effects of pressure on xylitol retention in a similar observation of NF

\subsection{Xylitol Concentration during Filtration}

Table 5 and Table 6 reveal comparisons of the composition of the initial feed concentration of $\mathrm{NF}$ and the final concentration of NF in the feed tank at a pressure of 5.5 barg during the concentration of the MFB solutions. We observed an increase in xylitol concentration from 5.69-6.07 $\mathrm{g} / \mathrm{L}$ in the initial feed to $7.94-9.34 \mathrm{~g} / \mathrm{L}$ in the final feed tank storage of NF. Considering the initial xylitol concentration of $2.8 \mathrm{~g} / \mathrm{L}$ in the MFB, the membrane process configuration of UF and NF gave a 2.8-3.3 fold increase in the xylitol concentration of the solution. If the batch-filtration time is longer and a higher initial concentration is used, further concentration of xylitol could be achieved. At the same time, the final NF retentate 
concentration of xylose and acetic acid were observed to be low.

Table 5 Comparison of the composition of the initial feed of NF (permeate of UF at pressure 1 barg) and the final feed of NF after the concentration of MFB solutions

\begin{tabular}{lcc}
\hline Concentration & Initial feed concentration $(\mathrm{g} / \mathrm{L})$ & Final feed concentration $(\mathrm{g} / \mathrm{L})$ \\
\hline Xylitol & 6.07 & 9.34 \\
Xylose & 3.87 & 1.29 \\
Acetic acid & 7.35 & 1.38 \\
\hline
\end{tabular}

Table 6 Comparisons of the composition of the initial feed of NF (permeate of UF at pressure $1.5 \mathrm{barg}$ ) and the final feed of NF after the concentration of MFB solutions

\begin{tabular}{lcc}
\hline Concentration & Initial feed concentration $(\mathrm{g} / \mathrm{L})$ & Final feed concentration $(\mathrm{g} / \mathrm{L})$ \\
\hline Xylitol & 5.69 & 7.94 \\
Xylose & 3.19 & 1.34 \\
Acetic acid & 2.73 & 1.63 \\
\hline
\end{tabular}

\section{CONCLUSION}

The results showed that the UF membrane can remove biomass cells from fermentation broth. UF showed great performance for the retention of biomass cells, in that no cells were observed in the UF permeate. An increase in the applied pressure did not significantly increase the steady-state UF fluxes of the UF permeate. Increasing the applied NF pressure tended to increase xylitol retention and increased the initial permeate flux, despite the faster decrease in the flux due to the resulting concentration polarization and membrane fouling.

The optimum test conditions were achieved by applying a UF pressure of 1 barg and an NF pressure of 5.5 barg, giving a 3.3-times xylitol concentration of the feed solution. Overall, the combination of both the UF and NF processes was shown to be a promising process configuration to purify and concentrate xylitol obtained from a fermentation process.

\section{ACKNOWLEDGEMENT}

This research was funded by the Directorate of Higher Education, Indonesian Ministry of National Education (DIKTI) under the scheme for Fundamental Research.

\section{REFERENCES}

Abels, C., Thimm, K., Wulfhorst, H., Antje, C.S, Matthias, W., 2013. Membrane-based Recovery of Glucose from Enzymatic Hydrolysis of Ionic Liquid Pretreated Cellulose. Bioresource Technology, Volume 149, pp. 58-64

Affleck, R.P., 2000. Recovery of Xylitol from Fermentation of Model Hydrolysate using Membrane Technology. Master's Thesis, State University of Virginia, Virginia, America

Ahsan, L., Jahan, M.S., Ni, Y., 2014. Recovering/Concentrating of Hemicellulosic Sugars and Acetic Acid by Nanofiltration and Reverse Osmosis from Prehydrolysis Liquor of Kraft Based Hardwood Dissolving Pulp Process. Bioresource Technology, Volume 155, pp. 111115

Cheryan, M., 1998. Ultrafiltration and Microfiltration Handbook. $2^{\text {nd }}$ Edition. Lancaster, England

Guirimand, G., Sasaki, K., Inokuma, K., Bamba, T., Hasunuma, T., Kondo, A., 2015. Cell Surface Engineering of Saccharomyces Cerevisiae Combined with Membrane Separation 
Technology for Xylitol Production from Rice Straw Hydrolysate. Appl Microbiol Biotechnol, Volume 100(8), pp. 3477-3487

Kresnowati, M.T.A.P., Desiriani, R., Wenten, I.G., 2017. Ultrafiltration of Hemicellulose Hydrolysate Fermentation Broth. In: AIP Conference Proceedings, Volume 1818, pp. 020024

Kresnowati, M.T.A.P., Setiadi, T., Tantra, T.M., David., 2016. Microbial Production of Xylitol from Oil Palm Empty Fruit Bunches Hydrolysate: Effects of Inoculum and pH. J.Eng. Technol. Sci, Volume 48(5), pp. 523-533

Li, Y., Shahbazi, A., Kadzere, C.T., 2006. Separation of Cells and Proteins from Fermentation Broth using Ultrafiltration. Journal of Food Engineering, Volume 75, pp. 574-580

Lyu, H., Fang, Y., Ren, S., Chen, K., Luo, G., Zhang, S., Chen, J., 2016. Monophenols Separation from Monosaccharides and Acids by Two-stage Nanofiltration and Reverse Osmosis in Hydrothermal Liquefaction Hydrolysates. Journal of Membrane Science, Volume 504, pp. 141-152

Mardawati, E., Wira, D.W., Kresnowati, M.T.A.P., Purwadi, R., Setiadi, T., 2015. Microbial Production of Xylitol from Oil Palm Empty Fruit Bunches Hydrolysate: The Effect of Glucose Concentration. Journal of the Japan Institute of Energy, Volume 94, pp. 769-774

Martınez, E.A., Silva, S.S., Almeida e Silva, J.B., Solenzal, A.I.N., Felipe, M.G.A., 2003. The Influence of $\mathrm{pH}$ and Dilution Rate on Continuous Production of Xylitol from Sugarcane Bagasse Hemicellulosic Hydrolysate by C. Guilliermondii. Process Biochemistry, Volume 38, pp. 1677-1683

Murthy, G.S., Sridhar, S., Shyam Sunder, M., Shankaraiah, B., Ramakrishn, M., 2005. Concentration of Xylose Reaction Liquor by Nanofiltration for the Production of Xylitol Sugar Alcohol. Separation and Purification Technology, Volume 44, pp. 205-211

Nguyen, N., Fargues, C., Guiga, W., Lameloise, M.L., 2015. Assessing Nanofiltration and Reverse Osmosis for the Detoxification of Lignocellulosic Hydrolysates. Journal of Membrane Science, Volume 487, pp. 40-50

Sasaki, K., Tsuge, Y., Sasaki, D., Hasunuma, T., Sakamoto, T., Sakihama, Y., Ogino, C., Kondo, A., 2014. Optimized Membrane Process to Increase Hemicellulosic Ethanol Production from Pretreated Rice Straw by Recombinant Xylose-fermenting Saccharomyces Cerevisiae. Bioresource Technology, Volume 169, pp. 380-386

Sjoman, E., Mantt, M., Nystrom, M., Koivikko, H., Heikkila, H., 2008. Xylose Recovery by Nanofiltration from Different Hemicellulose Hydrolyzate Feeds. Journal of Membrane Science, Volume 310, pp. 268-277

Weng, Y.H., Wei, H.J., Tsai, T.Y., Lin, T.., Wei, T.Y., Guo, G.L., Huang, C.P., 2010. Separation of Furans and Carboxylic Acids from Sugars in Dilute Acid Rice Straw Hydrolyzates by Nanofiltration. Bioresource Technology, Volume 101, pp. 4889-4894

Yadav, M., Mishra, D.K., Hwang, J.S., 2012. Catalytic Hydrogenation of Xylose to Xylitol using Ruthenium Catalyst on $\mathrm{NiO}$ Modified $\mathrm{TiO}_{2}$ Support. Applied Catalysis A: General, Volume 425, pp. 110-116

Zhou, F., Wang, C., Wei, J., 2013a. Separation of Acetic Acid from Monosaccharides by NF and RO Membranes: Performance Comparison. Journal of Membrane Science, Volume 429, pp. 243-251

Zhou, F., Wang, C., Wei, J., 2013b. Simultaneous Acetic Acid Separation and Monosaccharide Concentration by Reverse Osmosis. Bioresource Technology, Volume 131, pp. 349-356 